This document is confidential and is proprietary to the American Chemical Society and its authors. Do not copy or disclose without written permission. If you have received this item in error, notify the sender and delete all copies.

\title{
Electrochemical Detection and Quantification of Lithium Ions in Authentic Human Saliva Using $\mathrm{LiMn}_{2} \mathrm{O}_{4}$-modified Electrodes
}

\begin{tabular}{|r|l|}
\hline Journal: & ACS Sensors \\
\hline Manuscript ID & se-2019-01176h.R1 \\
\hline Danuscript Type: & Article \\
\hline Aubmitted by the & 08-Aug-2019 \\
\hline Complete List of Authors: & $\begin{array}{l}\text { Suherman, Alex; University of Oxford, Department of Chemistry, } \\
\text { Physical \& Theoretical Chemistry Laboratory } \\
\text { Rasche, Bertold; University of Oxford, Department of Chemistry } \\
\text { Godlewska, Beata; University of Oxford, Psychiatry } \\
\text { Nicholas, Philip; Sun Chemical Ltd, Sun Sens } \\
\text { Herlihy, Shaun; Sun Chemical Ltd, Sun Sens } \\
\text { Caiger, Nigel; Sun Chemical Ltd, Sun Sens } \\
\text { Cowen, Philip; University of Oxford, Psychiatry } \\
\text { Compton, Richard; University of Oxford, Department of Chemistry, } \\
\text { Physical \& Theoretical Chemistry Laboratory }\end{array}$ \\
\hline
\end{tabular}

\section{SCHOLARONE \\ Manuscripts}




\title{
Electrochemical Detection and Quantification of Lithium Ions in Authentic Human Saliva Using $\mathrm{LiMn}_{2} \mathrm{O}_{4}$-modified Electrodes
}

Alex L. Suhermana, Bertold Raschea, Beata Godlewska ${ }^{b}$, Philip Nicholas ${ }^{c}$, Shaun Herlihyc, Nigel Caigerc, Philip J. Cowen ${ }^{\mathrm{b}}$ and Richard G. Compton ${ }^{\mathrm{a},{ }^{*}}$

${ }^{a}$ Department of Chemistry, Physical and Theoretical Chemistry Laboratory, Oxford University, South Parks Road, Oxford, OX1 3QZ, UK.

b Department of Psychiatry, Oxford University, Oxford, OX3 7JX, UK.

c SunSens Department, Sun Chemical Ltd., The Ridge Factory, Yate, Bristol BS37 7AA, UK.

*Corresponding author:

Email : richard.compton@chem.ox.ac.uk

Phone : +44 (0) 1865275957

Fax : : +44(0) 1865275410

\begin{abstract}
We report an electrochemical sensor for the detection of lithium ions $\left(\mathrm{Li}^{+}\right)$in authentic human saliva at lithium manganese oxide $\left(\mathrm{LiMn}_{2} \mathrm{O}_{4}\right)$-modified glassy carbon electrodes (LMO-GCEs) and screenprinted electrodes (LMO-SPEs). The sensing strategy is based on an initial galvanostatic delithiation of LMO followed by linear stripping voltammetry (LSV) to detect the re-insertion $\mathrm{Li}^{+}$in the analyte. The process was investigated using powder X-ray diffraction (PXRD) and voltammetry. LSV measurements reveal a measurable lower limit of $50.0 \mu \mathrm{M}$ in both $\mathrm{LiClO}_{4}$ aqueous solutions and synthetic saliva samples, demonstrating the applicability of the proposed analytical method down to low $\mathrm{Li}^{+}$ concentrations. Four different samples of authentic human saliva were then analysed with the established sensing strategy using LMO-SPEs, showing good linearity over a concentration range up to $5.0 \mathrm{mM} \mathrm{Li}^{+}$with high reproducibility (RSD $<7 \%$ ) and applicability for routine monitoring purposes. The total time needed to analyse a sample is less than three minutes.
\end{abstract}

Keywords: authentic human saliva, $\mathrm{LiMn}_{2} \mathrm{O}_{4}$, lithium, galvanostatic delithiation, linear sweep voltammetry, screen-printed electrode 
Bipolar disorder (BD), also known as manic-depressive illness, is a recurrent mood disorder that causes unusual changes in affect, energy and activity levels from one extreme to another., ${ }^{1,2}$ According to the National Health Service (NHS) of the United Kingdom, lithium salts (normally administered as lithium carbonate) are a first-line treatment and officially approved for the management of BD. ${ }^{3}$ Lithium is also included on the $20^{\text {th }}$ World Health Organization (WHO) Essential Medicines List (EML) as one of the most effective and safe medicine needed to treat BD. ${ }^{4}$ During treatment, it is necessary to monitor the level of lithium $\left(\mathrm{Li}^{+}\right)$since the therapeutic range (0.5-0.8 mM in blood) is close to the levels associated with severe intoxication at $\geq 1.5 \mathrm{mM}$. $\mathrm{Li}^{+}$is lethal at concentrations of 2.0-2.5 mM. ${ }^{5,6,7}$ The monitoring of the $\mathrm{Li}^{+}$level is clearly an important aspect of the treatment of $\mathrm{BD}$, as toxicity and dose-related adverse effects can be avoided by dose adjustment or change in the dosage schedule. It is therefore currently necessary for clinicians to monitor their patient's levels of $\mathrm{Li}^{+}$regularly with repeated blood tests.

Monitoring of $\mathrm{Li}^{+}$ion levels in patients can also be achieved in saliva because it is correlated with the content in blood. Specifically, $\mathrm{Li}^{+}$ion level in saliva has been reported to be two/three times higher than in blood. ${ }^{5,8}$ Moreover, saliva is a preferable and more practical matrix for monitoring of $\mathrm{Li}^{+}$ ion levels because its collection is less stressful compared to the collection of blood and furthermore allows the patients to monitor their $\mathrm{Li}^{+}$ion level for themselves. ${ }^{9,10,11}$ The effective therapeutic $\mathrm{Li}^{+}$ range in saliva is 1.5-2.5 mM.,12 This range must be accurately monitored by a highly sensitive analytical method that is reliable and simple to ensure adequate and safe treatment.

Several analytical methods have been described for $\mathrm{Li}^{+}$detection in different kinds of samples including, but not limited to, high-performance liquid chromatography (HPLC) ${ }^{13}$, capillary electrophoresis ${ }^{14}$, inductively coupled plasma-atomic emission spectroscopy (ICP-AES) ${ }^{15}$, fluorescence-based sensor ${ }^{16}$, secondary ion mass spectrometry ${ }^{17}$, spectrophotometry ${ }^{7}$ and potentiometry ${ }^{18,19}$. These methods are reliable and have good sensitivity. However, they may involve extensive sample pre-treatment and expensive instruments. In favourable cases, voltammetry could provide simpler, cost-effective, user-friendly analysis and the possibility to adapt the process for in situ analysis; making it an ideal option for the routine monitoring purpose. The effective use of various voltammetric methods have been reported for the detection of glucose $\mathrm{e}^{20}$, bisphenol $\mathrm{A}^{21}$, silver nanoparticles ${ }^{22}$, various heavy metal ions ${ }^{23,24,25}, \operatorname{cortisol}^{26,27}$, amphetamines ${ }^{28}$, thiocyanate ${ }^{29}, \Delta^{9}$ tetrahydrocannabinol ${ }^{30}$, glutathione ${ }^{31,32}$, uric acid ${ }^{33}$, selegiline $e^{34}$ and modafinil ${ }^{35}$ in either synthetic or authentic human saliva.

In this paper, a linear sweep voltammetry (LSV) method is employed to detect $\mathrm{Li}^{+}$in aqueous solution, synthetic saliva and authentic human saliva samples, using lithium manganese oxide $\left(\mathrm{LiMn}_{2} \mathrm{O}_{4}\right)$-modified electrodes. The spinel-type $\mathrm{LiMn}_{2} \mathrm{O}_{4}$ (LMO) is employed as a cathode material for high-performance lithium ion rechargeable batteries. ${ }^{36}$ LMO can also be used for lithium extraction and insertion from aqueous media due to its high selectivity for $\mathrm{Li}^{+}$, chemical stability, low cost and non-toxic nature. ${ }^{37,38}$ Furthermore, the delithiation kinetics from single LMO particles has been studied 
in an aqueous solution by the nano-impacts technique. ${ }^{39}$ In the present work, LMO is used as an electrode surface modifier for $\mathrm{Li}^{+}$detection ("lithiation") through first a galvanostatic partial delithiation and a subsequent LSV measurement. Note that the use of solids to provide a selective approach for lithium in the presence of other alkali metals can be compared to the use of $\mathrm{Li}^{+}$ ionophore-based polymeric membrane, as reviewed by Zdrachek and Bakker ${ }^{40}$, but with the advantage that they may be easily screen-printed as demonstrated in this paper. Moreover, the use of solids may provide a corresponding good selectivity but with significant lower cost and synthetic requirements.

The transfer of the optimised sensing strategy onto disposable screen-printed electrodes (LMO-SPE) was assessed in authentic human saliva sample from four healthy volunteers. The results show distinct signals against background with good reproducibility, as well as making it simpler and accessible for point-of-care diagnosis and routine monitoring of $\mathrm{Li}^{+}$ion levels in saliva of patients for example with bipolar disease.

\section{EXPERIMENTAL SECTION}

Chemical Reagents. Lithium manganese oxide $\left(\mathrm{LiMn}_{2} \mathrm{O}_{4}\right.$, spinel type) were sourced commercially, both $\geq 99 \%$ purity (Sigma Aldrich, UK) and 99.5\% purity (Alfa Aesar, UK). Lithium perchlorate $\left(\mathrm{LiClO}_{4}\right.$, p.a., $\left.\geq 98.0 \%\right)$, lithium chloride ( $\left.\mathrm{LiCl}, \geq 99.98 \%\right)$, sodium perchlorate $\left(\mathrm{NaClO}_{4}\right.$, $\geq 98.0 \%$ ), sodium chloride ( $\mathrm{NaCl}, \geq 99.0 \%$ ), potassium chloride ( $\mathrm{KCl}, \geq 99.0 \%$ ), calcium chloride $\left(\mathrm{CaCl}_{2}\right.$, $\geq 97.0 \%)$ and magnesium chloride $\left(\mathrm{MgCl}_{2}, 98 \%\right)$ were used as received (Sigma Aldrich, UK). Synthetic saliva (pH $6.8 \pm 0.1$ ) was sourced from Synthetic Urine e.K. (Eberdingen-Nußdorf, Germany). The proprietary formulation of the synthetic saliva reflects the standardised production process pursuant of DIN53160-1.41 The electrode surface modifier was made of a mixture of $\mathrm{LiMn}_{2} \mathrm{O}_{4}$, carbon black (M 1100, Monarch ${ }^{\circledR}$ donated by Cabot Performance, Billerica, USA) and polyvinylidene difluoride (PVDF, Solef S5130, Solvay, Belgium) with a percent weight ratio of 80:10:10, respectively, and diluted in Nmethylpyrrolidone (Sigma Aldrich, UK). ${ }^{39}$ The LMO slurry was stirred overnight with a magnetic stirrer. Where it is referred to water, deionised water with a resistivity of $18.2 \mathrm{M} \Omega \mathrm{cm}$ at $298 \mathrm{~K}$ (Millipore, Millipak Express 20, Watford, UK) was used. A high purity $\mathrm{N}_{2}$ flow (BOC Gases plc, UK) was used to remove oxygen thoroughly in all aqueous solutions (see Electrochemical Behaviour of LMOGCE in Aqueous Solution) prior to the electrochemical measurements. Note, neither synthetic saliva nor authentic human saliva were bubbled with $\mathrm{N}_{2}$ (see Detection of $\mathrm{Li}^{+}$in Synthetic Saliva and 3.3) as the analysis does not require the removal of oxygen or other dissolved from the saliva.

Electrochemical Procedure. Electrochemical measurements were performed in a thermostatted $\left(25 \pm 1^{\circ} \mathrm{C}\right)$ Faraday cage using a $\mu$-Autolab III potentiostat/galvanostat (Autolab B.V., Utrecht, The Netherlands) and data acquisition was controlled by GPES software version 4.9. A standard three-electrode system was used by functioning a $3 \mathrm{~mm}$ diameter glassy carbon (GCE, $\mathrm{CH}$ Instruments, Inc., USA) or a $2 \mathrm{~mm}$ thick $20 \mathrm{~mm}$ diameter glassy carbon disc (GCD, SIGRADUR G, Hochtemperatur-Werkstoffe GmbH, Germany), a platinum wire (Goodfellow Cambridge Ltd., UK) and a 
saturated calomel electrode (SCE, ALS distributed by BASi, Japan) as working, counter and reference electrode, respectively. The GCE or GCD was cleaned by mechanical polishing on soft lapping pads using diamond spray (Kemet International Ltd, Kent, UK) of sizes 3, 1 and 0.1 micron. The freshly polished GCE or GCD were modified by drop casting $5.0 \mu \mathrm{l}$ of the LMO slurry and annealing it at $65{ }^{\circ} \mathrm{C}$ for 10 min to evaporate the solvent, resulting in a LMO-GCE or LMO-GCD electrode, respectively.

Electrochemical studies of LMO-GCE in aqueous solution were first conducted by cyclic voltammetry (CV). The LMO-GCE was immersed in a solution of $1.0 \mathrm{M} \mathrm{LiClO}_{4}$ and voltammograms were recorded by sweeping the potential from $0.0 \mathrm{~V}$ to $1.2 \mathrm{~V}$ and back to $0.0 \mathrm{~V}$ vs SCE at different scan rates. The influence of the use of "thermostatted vessel" (Faraday cage) and temperature were also assessed by performing CV (as described above) at a scan rate of $0.5 \mathrm{mV} \mathrm{s}^{-1}$. Next, the LMO-GCE was immersed in solutions of $\mathrm{LiClO}_{4}, \mathrm{LiCl}, \mathrm{NaClO}_{4}, \mathrm{NaCl}, \mathrm{KCl}$ and $\mathrm{MgCl}_{2}$, each $1.0 \mathrm{M}$ respectively, and then the potential was swept as described above at a scan rate of $0.5 \mathrm{mV} \mathrm{s}^{-1}$. The concentration of $1.0 \mathrm{M}$ was selected in order to obtain clear signals for the delithiation steps. In further CV experiments, initially a reductive sweep was performed after holding the potential of $1.0 \mathrm{~V}$ for zero or $10 \mathrm{~min}$ (delithiation step) by immersing the LMO-GCE in $50.0 \mathrm{mM} \mathrm{LiClO}_{4}$ solution and sweeping the potential from $1.0 \mathrm{~V}$ to $0.0 \mathrm{~V}$ and back to $1.0 \mathrm{~V}$ vs SCE at different scan rates.

The selectivity studies were performed using LSV by immersing the LMO-GCE either in a solution of $\mathrm{NaCl}, \mathrm{KCl}, \mathrm{CaCl}_{2}$ or $\mathrm{MgCl}_{2}, 10.0 \mathrm{mM}$ each respectively, or in a mixture of these. Note that concentration of $10.0 \mathrm{mM}$ was selected in order to study the lithiation step, which underpins the sensor performance for practical purposes. The LSV was recorded after delithiation step of $10 \mathrm{~min}$ at $1.0 \mathrm{~V}$ vs SCE, followed by sweeping the potential directly to $0.0 \mathrm{~V}$ vs SCE at a scan rate of $5.0 \mathrm{mV} \mathrm{s}^{-1}$.

In this work, the lower scan rate of $0.5 \mathrm{mV} \mathrm{s}^{-1}$ is selected when performing $\mathrm{CV}$ for modified electrode in both aqueous solution and synthetic saliva. The aim of using this low scan rate is to study the electrode response within delithiation steps. Meanwhile, the higher scan rate of $5.0 \mathrm{mV} \mathrm{s}^{-1}$ selected to speed up the lithiation step ( $\mathrm{Li}^{+}$detection) of the sensor in aqueous solution, synthetic saliva and authentic human saliva. Therefore, by improving the scan rate $\left(5.0 \mathrm{mV} \mathrm{s}^{-1}\right)$ reasonable analytical times can be achieved without compromising the sensitivity or selectivity of the measurement.

Electrochemical studies of LMO-GCE in synthetic human saliva were evaluated by CV at different scan rates. Next, both LMO-GCE and LMO-GCD were analysed by performing galvanostatic measurements with a current density of $8.6 \mathrm{~mA} \mathrm{~cm}^{-2}$ (SI. Calculation, which is based on the geometrical area of the electrode, not the particle surface area) at different times in order to optimise the delithiation prior to the detection of $\mathrm{Li}^{+}$. The optimisation of chronoamperometric time was conducted in $5.0 \mathrm{mM} \mathrm{Li}^{+}$-spiked synthetic saliva through LSV at a scan rate of $5.0 \mathrm{mV} \mathrm{s}^{-1}$. The powder X-ray diffraction (PXRD) measurements were performed to analyse the structure of the LMO before and after the delithiation step at different times. PXRD analysis were done on a PANalytical Empyrean instrument operating in Bragg-Brentano geometry with a curved Ge(111) Johansson monochromator to select $\mathrm{CuK}_{\alpha 1}=1.54060 \AA$ radiation with a step size of $0.013^{\circ} 2 \theta$. The LMO-GCD samples were 
prepared as described above and the disc was directly mounted on a sample holder. The data was evaluated with WinX ${ }^{\text {Pow }}$ software. ${ }^{42}$ The PXRD results will be discussed in the section Detection of $\mathrm{Li}^{+}$ in Synthetic Saliva. All figures were prepared with OriginLab2017.43 A measurable lower limit of the LMO-GCE was assessed in synthetic saliva sample through galvanostatic delithiation followed by LSV.

As a proof of concept, we demonstrated the application of the established sensing strategy for analysis of $\mathrm{Li}^{+}$in authentic human saliva samples. The measurements of authentic human saliva samples were performed using $\mathrm{LiMn}_{2} \mathrm{O}_{4}$-modified screen-printed electrode (LMO-SPE) comprised of three electrodes, which were screen printed by Sun Chemical Ltd (Bristol, UK). The reference electrode was a silver-silver chloride electrode formed using a 60:40 weight ratio of silver to silver chloride, stabilised by $1.0 \mathrm{M} \mathrm{Cl}^{-}$in aqueous solution, $0.02 \mathrm{M} \mathrm{Cl}^{-}$in synthetic saliva ${ }^{41}$ and by natural $\mathrm{Cl}^{-}$ content found in authentic human saliva which is similar to the value in synthetic saliva. The counter electrode was made of carbon (graphite/carbon black), whilst the working electrode was made from carbon and $\mathrm{LiMn}_{2} \mathrm{O}_{4}$.

Authentic Human Saliva Sample Measurements. The collection of authentic human saliva samples is in accordance with the Approved Procedure 24: IDREC 24 Version 3.0 from the Central University Research Ethics Committee (CUREC), Oxford University. ${ }^{44}$ The samples were collected from four healthy volunteers using Salivetts ${ }^{\circledR}$ (Sarstedt, Germany). Each volunteer chewed the swabs from the Salivetts $₫$ for 1 min and then the Salivetts ${ }^{\circledR}$ containing the respective swabs were centrifuged at $1,000 \times \mathrm{g}$ (equivalent to 2,400 rpm) for $2 \mathrm{~min}$ at $20{ }^{\circ} \mathrm{C} .{ }^{45}$ Centrifuged samples were processed as soon as possible in a Class II biohazard hood. Subsequently, a ca. $50.0 \mu \mathrm{L}$ of sample was deposited onto the LMO-SPE surface, covering all three electrodes. The analysis was conducted by standard addition method in triplicate, each from the same time of sample collection (see below).

\section{RESULTS AND DISCUSSION}

This section outlines the method for the electrochemical detection and quantification of $\mathrm{Li}^{+}$ion in aqueous solution, synthetic saliva and authentic human saliva samples. We first analyse electrochemical characterisations of the LMO-GCE in $1.0 \mathrm{M} \mathrm{LiClO}_{4}$ aqueous solutions inside and outside of a Faraday cage, at various temperatures and at various scan rates using CV. Then CV analysis of the LMO-GCE in solutions containing different cations were performed at a scan rate of $0.5 \mathrm{mV} \mathrm{s}^{-1}$. The selectivity in respect of possible interfering ions and the measurable lower limit of the LMO-GCE were analysed through linear sweep voltammetry (LSV). Second, the LMO-GCE performance was optimised by galvanostatic delithiation followed by a LSV measurement in a synthetic saliva. Finally, with the knowledge about the galvanostatic delithiation and the LSV we demonstrate the successful application of the LMO-SPE to detect $\mathrm{Li}^{+}$level in four different authentic human saliva.

Electrochemical Behaviour of LMO-GCE in Aqueous Solution. The LMO-GCE was immersed in a solution of $1.0 \mathrm{M} \mathrm{LiClO}_{4}$ and a CV was recorded by sweeping the potential from $0.0 \mathrm{~V}$ to $1.2 \mathrm{~V}$ vs SCE and back to $0.0 \mathrm{~V}$ at a scan rate of $0.5 \mathrm{mV} \mathrm{s}^{-1}$ (Figure 1, black curve). On the first forward scan, 
two quasi-reversible redox waves (as judged by the peak-to-peak potential separation) are observed at a potential of ca. $0.87 \mathrm{~V}$ vs SCE (peak-A1) and ca. $1.00 \mathrm{~V}$ vs SCE (peak-A2). Peak-A1 and peak-A2 correspond to the two delithiation steps in $\mathrm{LiMn}_{2} \mathrm{O}_{4}$. The first step (peak-A1) yields a phase with the approximate composition $\mathrm{Li}_{0.5} \mathrm{Mn}_{2} \mathrm{O}_{4}$ and the second step (peak-A2) the lithium free $\lambda-\mathrm{MnO}_{2} \cdot{ }^{46} \mathrm{On}$ the backward scans, two peaks ( $\mathrm{C} 2$ and $\mathrm{C} 1$ ) were observed at ca. $-0.86 \mathrm{~V}$ and ca. $-0.67 \mathrm{~V}$ vs SCE that correspond to the re-insertion of the $\mathrm{Li}^{+}$(lithiation) into the spinel structure of LMO. ${ }^{39}$
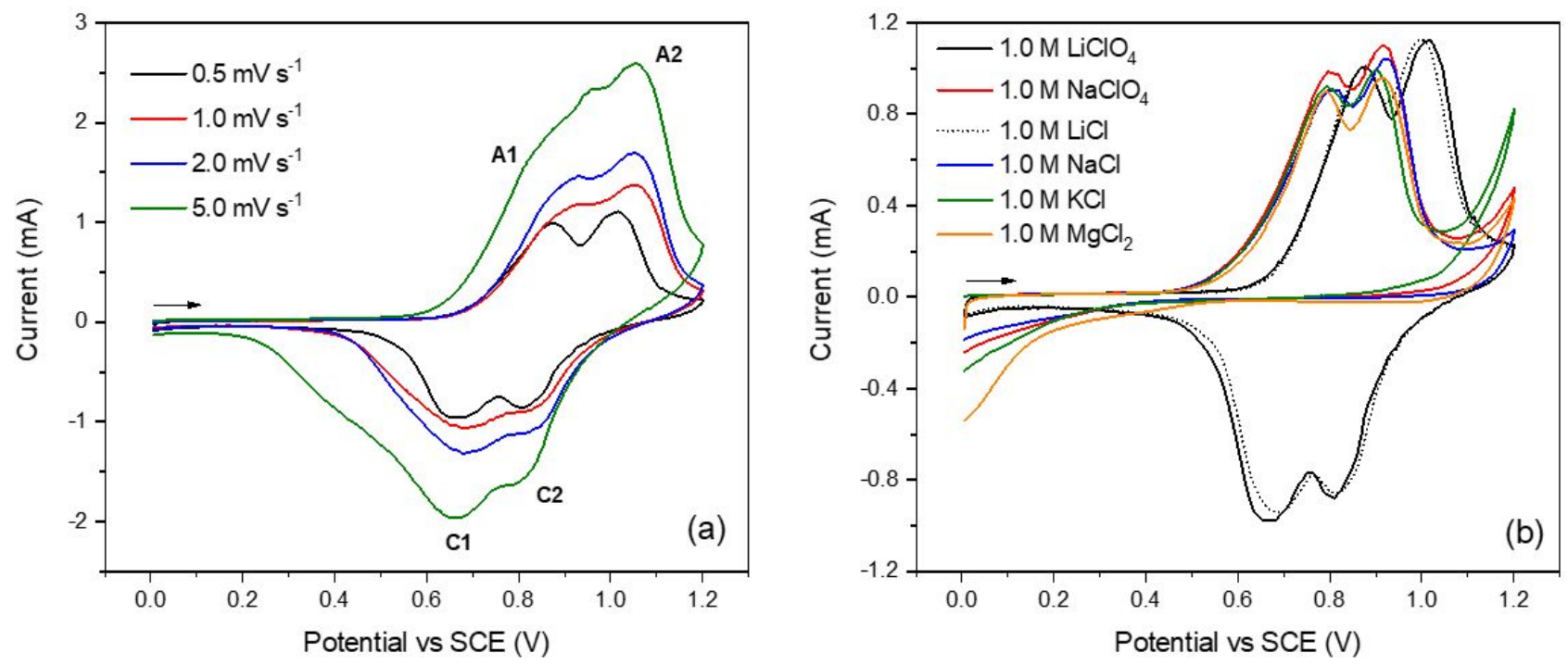

Figure 1. CV of LMO-GCE immersed in (a) $1.0 \mathrm{M} \mathrm{LiClO}_{4}$ at different scan rates and (b) different aqueous solutions at a scan rate of $0.5 \mathrm{mV} \mathrm{s}^{-1}$.

The use of a thermostatted vessel or a Faraday cage follows standard analytical practice; it is not needed for the analytical measurement. To confirm this, the LMO-GCE immersed in $1.0 \mathrm{M} \mathrm{LiClO}_{4}$ both inside (at $25{ }^{\circ} \mathrm{C}$ ) and outside (at ambient temperature) of the Faraday cage. The CVs were recorded by sweeping the potential from $0.0 \mathrm{~V}$ to $1.2 \mathrm{~V}$ vs SCE and back to $0.0 \mathrm{~V}$ vs SCE at a scan rate of $0.5 \mathrm{mVs}^{-1}$. As shown in Figure SI.1a, the two forward peaks resulting from the experiment performed outside the Faraday cage (solid red curve) are clear; all redox waves can be distinguished and seen at the same peak potential position, suggesting good reproducibility of the modified electrode. The Faraday cage was not used for screen-printed electrode (SPE) measurements, mimicking the conditions for potential sensor applications outside the laboratory. In addition to this, the temperature influence on the electrode response was verified by performing CV of the LMO-GCE immersed in a solution of $1.0 \mathrm{M} \mathrm{LiClO}_{4}$ at $20^{\circ} \mathrm{C}, 25^{\circ} \mathrm{C}$ and $35^{\circ} \mathrm{C}$, all carried out inside the thermostatted Faraday cage. $\mathrm{CV}$ was performed as described above. The resulting cyclic voltammograms are very similar for all temperatures (Figure SI.1b). The results suggest that the temperature does not significantly affect the modified electrode response, at least over the temperature range studied.

Next, the effect of scan rate was studied. The LMO-GCE was immersed in $1.0 \mathrm{M} \mathrm{LiClO}_{4}$ and CVs were undertaken by sweeping the potential at $0.0 \mathrm{~V}$ to $1.2 \mathrm{~V}$ vs SCE and back to $0.0 \mathrm{~V}$ vs SCE at scan rates of $0.5,1.0,2.0$ and $5.0 \mathrm{mV} \mathrm{s}^{-1}$. Note that each experiment was undertaken using a freshly 
prepared LMO-GCE and degassed solution. As shown in Figure 1a, the two forward peaks can be distinguished using a scan rate of $0.5 \mathrm{mV} \mathrm{s}^{-1}$. Higher scan rates result in distorted voltammograms likely due to the kinetic limitations of the permeation of $\mathrm{Li}^{+}$through the deposited $\mathrm{LMO}$ at the electrode surface. Note that this low scan rate is exclusively used for CV experiments when the delithiation steps are studied (see below). Figure SI.2 presents a plot of peak current vs scan rate with an $\mathrm{R}^{2}=0.999$ and $\mathrm{R}^{2}=0.993$ for peak-A1 and peak-A2, respectively. The two linear dependencies of the peak current values on the scan rate suggest that the delithiation step is a surface-controlled process.

Next, the LMO-GCE was placed in solutions of $\mathrm{LiClO}_{4}, \mathrm{NaClO}_{4}, \mathrm{LiCl}, \mathrm{NaCl}, \mathrm{KCl}$ or $\mathrm{MgCl}_{2}$ at a concentration of $1.0 \mathrm{M}$ for each cation. The CVs were recorded in the same potential window (see above) with a scan rate of $0.5 \mathrm{mV} \mathrm{s}^{-1}$. As shown in Figure $1 \mathrm{~b}$, oxidation peaks are observed in all solutions but the peak potentials of both peak-A1 and peak-A2 are shifted to more positive values by ca. $60 \mathrm{mV}$ and $90 \mathrm{mV}$, respectively, in $\mathrm{LiClO}_{4}$ and $\mathrm{LiCl}$ compared to other solutions. These forward peaks indicate the delithiation steps are exclusively related to the oxidation of the manganese centres of the $\mathrm{LiMn}_{2} \mathrm{O}_{4}$. That two forward peaks appear at more negative potentials (for $\mathrm{NaClO}_{4}, \mathrm{NaCl}, \mathrm{KCl}$ and $\mathrm{MgCl}_{2}$ solutions), suggests an easier expulsion of lithium cations out of the LMO structure. The backward peaks $\mathrm{C} 2$ and $\mathrm{C} 1$ (the lithiation steps) are only observed in $\mathrm{LiClO}_{4}$ and $\mathrm{LiCl}$ solutions (Figure $1 \mathrm{~b}$, solid and dotted black curves). Therefore, lithiation only occurs if the bulk solution contains $\mathrm{Li}^{+}$.

The lithiation process was next studied at different delithiation step times under different scan rates. First, the LMO-GCE was immersed in a solution of $50.0 \mathrm{mM} \mathrm{KCl}$ or $50.0 \mathrm{mM} \mathrm{LiClO}_{4}$. The potential was held at $1.0 \mathrm{~V}$ vs SCE for either zero or $10 \mathrm{~min}$ followed by sweeping the potential from $1.0 \mathrm{~V}$ to $0.0 \mathrm{~V}$ vs SCE and back to $1.0 \mathrm{~V}$ vs SCE, at a scan rate of $5.0 \mathrm{mV} \mathrm{s}^{-1}$. As shown in Figure SI.3a (solid and dotted red curves), two backward peaks are observed at the peak potential of ca. $-0.64 \mathrm{~V}$ and ca. $0.42 \mathrm{~V}$ vs SCE denoted as peak-C2 and peak-C1, respectively. Consistently, in absence of $\mathrm{Li}^{+}$in the solution, no backward peaks were observed. The peak current values increase with lengthier delithiation step from ca. $0.1 \mathrm{~mA}$ to ca. $0.2 \mathrm{~mA}$ for peak-C2 and ca. $0.2 \mathrm{~mA}$ to ca. $0.3 \mathrm{~mA}$ for peak-C1. Second, the LMO-GCE was immersed in a solution of $50.0 \mathrm{mM} \mathrm{LiClO}_{4}$, the potential held at $1.0 \mathrm{~V}$ vs SCE for $10 \mathrm{~min}$ and then CVs were recorded in the same potential window (see above) at scan rates of 0.5 , 2.0, 5.0 and $10 \mathrm{mV} \mathrm{s}^{-1}$. As shown in Figure SI.3b, the two backward peaks are not clearly seen at scan rates above $5.0 \mathrm{mV} \mathrm{s}^{-1}$. The result indicates that the lithiation step is likely limited to the low permeation of $\mathrm{Li}^{+}$and slow absorption kinetics of $\mathrm{Li}^{+}$into the $\mathrm{LMO}$, at least for the $\mathrm{LiClO}_{4}$ concentration studied. Therefore, for the analytical measurements reported below, a delithiation step of 10 min and a scan rate of $5.0 \mathrm{mV} \mathrm{s}^{-1}$ were adopted.

The selectivity of the LMO-GCE towards the ion of interest $\left(\mathrm{Li}^{+}\right)$in the presence of potentially interfering ions, such as $\mathrm{Na}^{+}, \mathrm{K}^{+}, \mathrm{Ca}^{2+}$ and $\mathrm{Mg}^{2+}$, was investigated next. To assess this, a LMO-GCE was exposed to $10.0 \mathrm{mM}$ of $\mathrm{LiClO}_{4}, \mathrm{NaCl}, \mathrm{KCl}, \mathrm{CaCl}_{2}$ or $\mathrm{MgCl}_{2}$, respectively and $\mathrm{LSV}$ was recorded by employing a delithiation step of $10 \mathrm{~min}$ at $1.0 \mathrm{~V}$ vs SCE followed by sweeping the potential from $1.0 \mathrm{~V}$ 
to $0.0 \mathrm{~V}$ vs SCE at a scan rate of $5.0 \mathrm{mV} \mathrm{s}^{-1}$. As shown in Figure SI.4, the backward peak is observed at all studied solutions namely at a peak potential of $0.42 \mathrm{~V}, 0.54 \mathrm{~V}, 0.65 \mathrm{~V}, 0.60 \mathrm{~V}$ and $0.57 \mathrm{~V}$ vs SCE, respectively. The result indicates that these cations may insert into the LMO structure during the LSV scan. To validate the sensor's selectivity, the LMO-GCE was assessed in the presence of binary and all cation mixtures, at selected concentration of $10.0 \mathrm{mM}$ for each cation. As shown in Figure 2 (black and red curves), two backward peaks were observed at a peak potential of ca. $0.65 \mathrm{~V}$ (or ca. $0.58 \mathrm{~V}$ in the red curve) and ca. $0.42 \mathrm{~V}$ vs SCE that correspond to other cations and $\mathrm{Li}^{+}$insertions, respectively. However, in the mixture of all cations (Figure 2, blue curve), no significant interference from these cations toward $\mathrm{Li}^{+}$was observed since only one backward peak is seen at a peak potential of ca. $0.42 \mathrm{~V}$ vs SCE. These results suggest that the LMO-GCE has a good selectivity towards $\mathrm{Li}^{+}$, if applied to mixtures of multiple cations, which reflects the conditions as found in authentic human saliva.

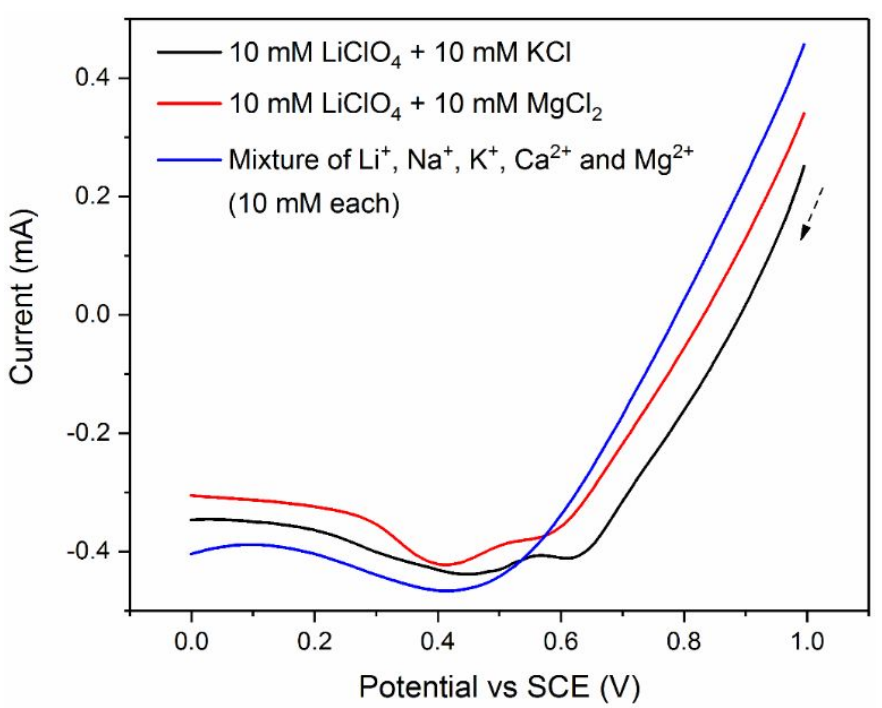

Figure 2. LSVs of LMO-GCE immersed in a mixture of multiple cations at a scan rate of $5.0 \mathrm{mV} \mathrm{s}^{-1}$.

Having defined the delithiation step time, scan rate and evaluated the selectivity of LMO-GCE, the sensitivity of the sensor is investigated in the following. The LMO-GCE was immersed in solutions of various $\mathrm{Li}^{+}$concentrations $(50.0 \mu \mathrm{M}$ to $5.0 \mathrm{mM})$ and LSVs were recorded by employing the method as described above (Figure 3a). The absolute current value at the cathodic peak position was used rather than using linear baseline correction to determine the peak current values as discussed below. As shown in Figure 3b, the absolute peak current values increase on increasing the $\mathrm{Li}^{+}$concentration. At concentrations below $50.0 \mu \mathrm{M} \mathrm{Li}^{+}$, the backward peak is no longer discernible, revealing the measurable lower limit of the LMO-GCE. For $\mathrm{Li}^{+}$detection, a linear peak current behaviour was observed at concentrations ranging from $50.0 \mu \mathrm{M}$ to $0.5 \mathrm{mM} \mathrm{Li}^{+}$with an $\mathrm{R}^{2}=0.996$ (Figure $3 \mathrm{~b}$, inset).

Following this, we further verified the linearity measurement using lithium manganese oxidemodified screen-printed electrode (LMO-SPE) in aqueous solution containing of various $\mathrm{LiClO}_{4}$ concentrations (Figure 3c). The LSV was recorded by employing a delithiation step of $10 \mathrm{~min}$ at potential $1.0 \mathrm{~V}$ vs $\mathrm{Ag} / \mathrm{AgCl}$ followed by sweeping the potential from $1.0 \mathrm{~V}$ to $0.0 \mathrm{~V} \mathrm{vs} \mathrm{Ag} / \mathrm{AgCl}$ at a scan 
rate of $5.0 \mathrm{mV} \mathrm{s}^{-1}$. As shown in the Figure 3d, the LMO-SPE shows an excellent linearity from $50.0 \mu \mathrm{M}$ to $5.0 \mathrm{mM}$, suggesting high applicability of the sensor to determine the $\mathrm{Li}^{+}$level within the therapeutic range of 1.5-2.5 mM. The practicability of the LMO-SPE will be discussed further in the section Detection of $\mathrm{Li}^{+}$in Authentic Human Saliva for the analysis of authentic human saliva.
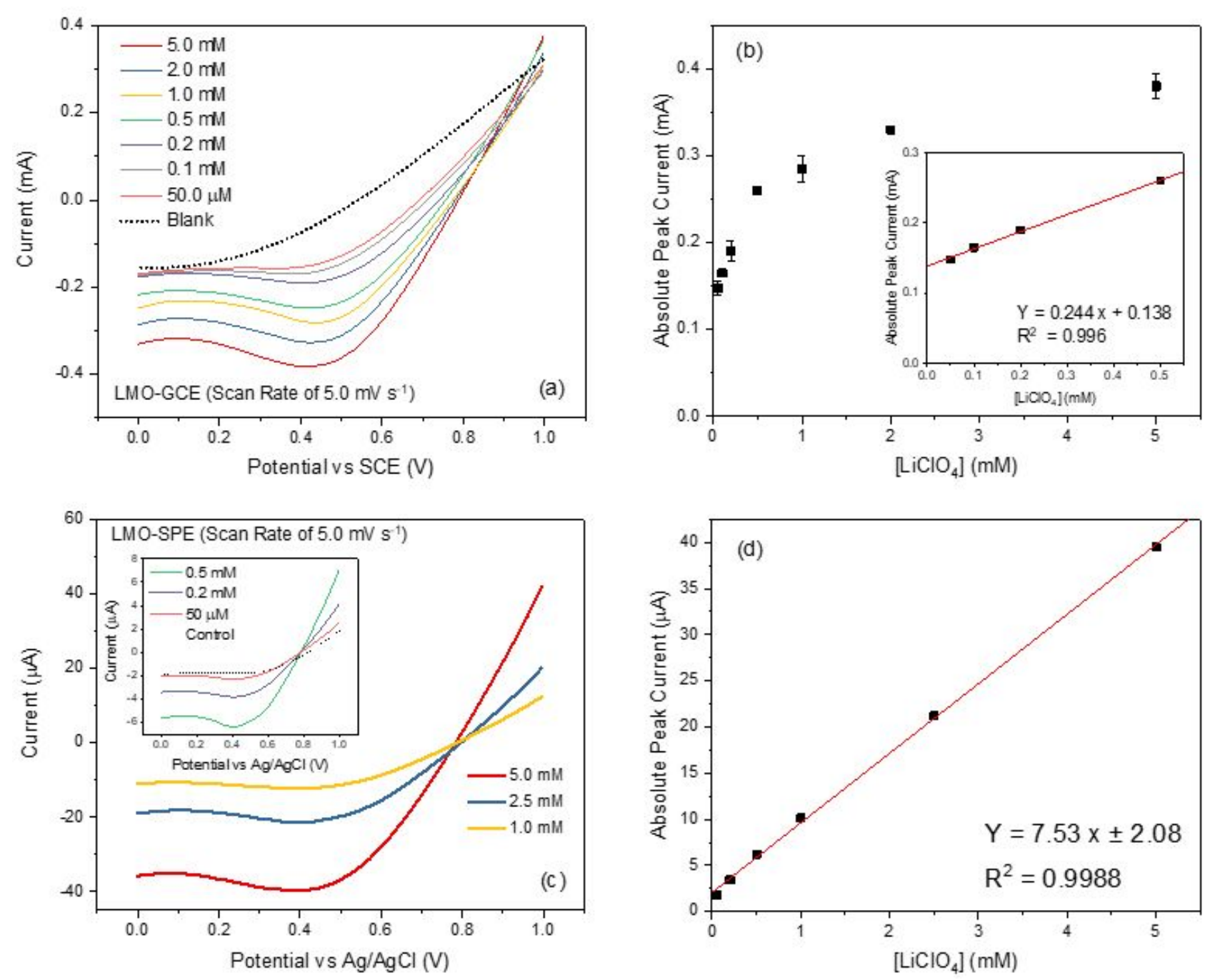

Figure 3. Measurable lower limit and linearity analyses of the modified electrodes immersed in different $\mathrm{LiClO}_{4}$ concentrations: (a) LSVs of LMO-GCE, (c) LSVs of LMO-SPE. (b) and (d) are the plot of the peak current values against various $\mathrm{LiClO}_{4}$ concentrations, generating from (a) and (c), respectively.

The above demonstrates a possible sensing method of $\mathrm{Li}^{+}$in an aqueous solution. However, the identified required potentiostatic delithiation step of $10 \mathrm{~min}$ at $1.0 \mathrm{~V}$ vs SCE before LSV being recorded is disadvantageous for the routine monitoring of samples. In the following, we show that this aspect can be improved by performing galvanostatic delithiation followed by LSV measurement.

Detection of $\mathbf{L i}^{+}$in Synthetic Saliva. The components of commercial synthetic saliva recipes vary depending on the supplier (Table SI.1). In this work, the synthetic saliva used contains inorganic ions such as $\mathrm{Mg}^{2+}, \mathrm{Ca}^{2+}, \mathrm{K}^{+}, \mathrm{Cl}^{-}, \mathrm{CO}_{3}{ }^{2-}, \mathrm{HPO}_{4}{ }^{2-}$ and unknown organic substances in order to adjust the viscosity level and pH $6.8 \pm 0.1{ }^{41}$ Note that authentic human saliva is primarily composed of water 
(99\%), several inorganic $\left(\mathrm{Na}^{+}, \mathrm{K}^{+}, \mathrm{Ca}^{2+}, \mathrm{Cl}^{-}, \mathrm{HPO}_{4}{ }^{2-}\right.$, etc.) and organic (uric acid, creatine, etc.) substances and others. ${ }^{11}$ This section will describe the electrochemical behaviour of the LMO-GCE in synthetic saliva, the optimisation of the sensing performance via galvanostatic delithiation-LSV and the sensitivity of the sensor.

First, the LMO-GCE was immersed in synthetic saliva and then CV was recorded by sweeping the potential from $0.0 \mathrm{~V}$ to $1.2 \mathrm{~V}$ vs SCE and back to $0.0 \mathrm{~V}$ at a scan rate of $0.5 \mathrm{mV} \mathrm{s}^{-1}$. Note that the synthetic saliva was not bubbled with $\mathrm{N}_{2}$ in order to better reflect conditions for practical purposes (direct-and-quick use of sensor in authentic human saliva). As shown in Figure SI.5, the resulting peak significantly decreased after 10 minutes bubbling with $\mathrm{N}_{2}$. Moreover, we also observed that synthetic saliva becomes whitish or opaque if bubbled with $\mathrm{N}_{2}$ thoroughly before the voltammetric measurement. This whitish or opaque colour of synthetic saliva after $\mathrm{N}_{2}$ bubbling is likely caused by the denaturation of protein due to mechanical stress. As shown in Figure SI.6a, one oxidation peak is seen at a potential of ca. $1.0 \mathrm{~V}$ vs SCE that probably corresponds to the two delithiation steps of deposited LMO on the electrode surface. No backward peaks are observed on the backward CV scan, suggesting no $\mathrm{Li}^{+}$ions (from the delithiation) re-insert back into the spinel structure of LMO. However, the cyclic voltammogram becomes distorted when applying higher scan rates, or even at $5.0 \mathrm{mV} \mathrm{s}^{-1}$ (Figure SI.6b), and "absorption" of unknown species (from components of the synthetic saliva) may arise as shown in a backward peak at peak potential of ca. $0.5 \mathrm{~V}$ vs SCE.

Second, the LMO-GCE was immersed either in $1.0 \mathrm{M} \mathrm{LiClO}_{4}$ solution or in synthetic saliva, and then galvanostatic delithiation was performed at an applied current density of $8.6 \mathrm{~mA} \mathrm{~cm}{ }^{-2}$ for particular period. In $1.0 \mathrm{M} \mathrm{LiClO}_{4}$ solution, two delithiation steps were found at ca. 0-420 s (up to first plateau) and ca. 420-1800 s (up to second plateau) (Figure 4a, red curve). Meanwhile, in synthetic saliva two delithiation steps were found at ca. 0-2000 s (up to first plateau) and ca. 2000-4500 s (up to second plateau) (Figure 4a, black curve). The results suggest both delithiation steps in $1.0 \mathrm{M} \mathrm{LiClO}_{4}$ are faster than in synthetic saliva possibly due to the higher ionic strength. Subsequently, the LMO-GCE was immersed in $5.0 \mathrm{mM} \mathrm{Li}^{+}$-spiked synthetic saliva and then the galvanostatic delithiation with a current density of $8.6 \mathrm{~mA} \mathrm{~cm}{ }^{-2}$ was performed at different times, ranging from $20 \mathrm{~s}$ to $20 \mathrm{~min}$. In the same sample, immediately LSV measurements were performed by sweeping from the ending potential of the galvanostatic delithiation to $0.0 \mathrm{~V}$ vs SCE at a scan rate of $5.0 \mathrm{mV} \mathrm{s}^{-1}$. As shown in Figure $4 \mathrm{~b}$, the response in the LSV becomes broadened for very long delithiation times and weaker for very short delithiation times. After a galvanostatic delithiation of $45 \mathrm{~s}$ (within the first plateau of the delithiation) the signal is very sharp and the peak current already close to values at longer times. Indeed, $45 \mathrm{~s}$ is also a realistic time scale of analysis for routine monitoring purposes and was therefore selected for all further experiments described below. 

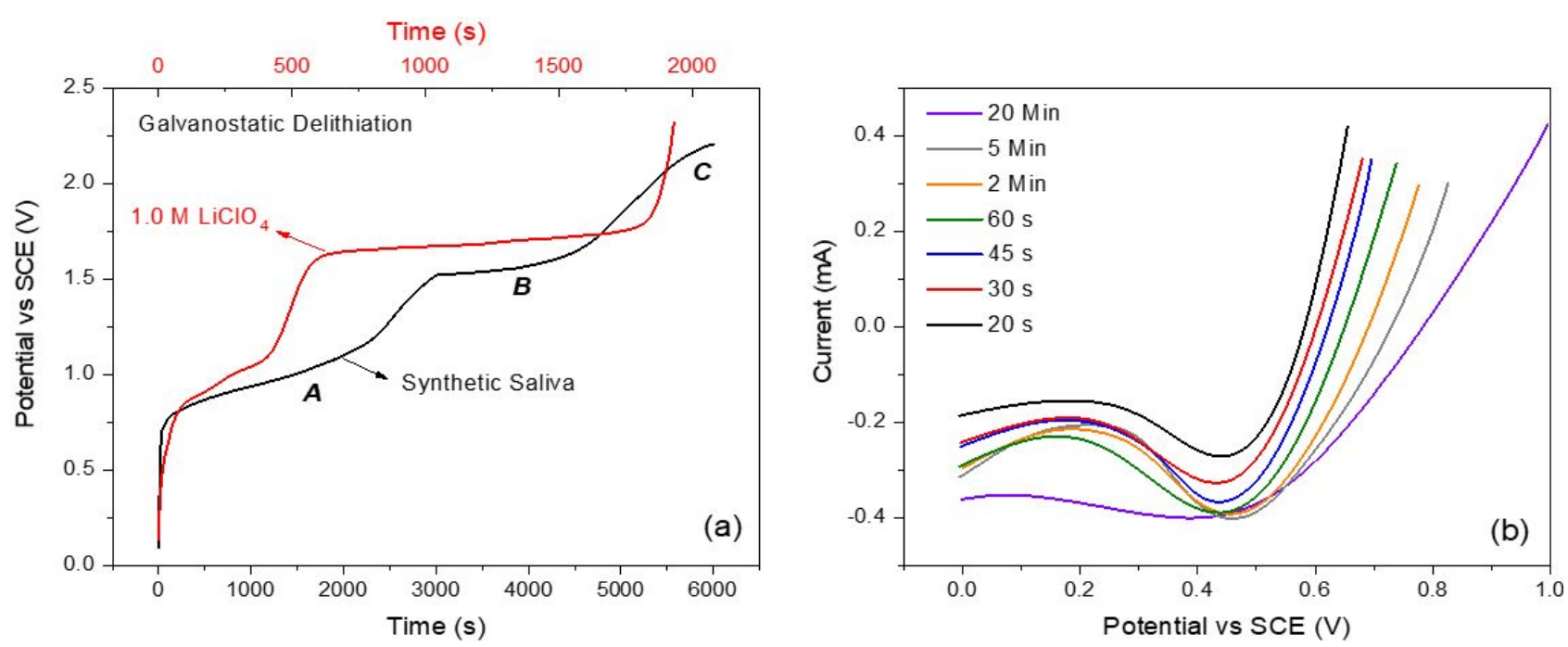

Figure 4. Optimising galvanostatic delithiation time. (a) Comparison of galvanostatic delithiation response of LMO-GCE immersed in $1.0 \mathrm{M} \mathrm{LiClO}_{4}$ vs synthetic saliva, (b) LSVs of LMO-GCE in $5.0 \mathrm{mM} \mathrm{Li}^{+}$-spiked synthetic saliva at a scan rate of $5.0 \mathrm{mV} \mathrm{s}^{-1}$.

An explanation for the different responses during the lithiation after different times in the galvanostatic delithiation can be found in the structural changes of LMO concomitant with the delithiation process. The structural changes of LMO before and after the delithiation steps were studied using the powder X-ray diffraction (PXRD) analysis, which requires compatible substrate (disc type) for the measurements. To assess this, a freshly polished glassy carbon disc (GCD) was first modified by drop casting $5.0 \mu \mathrm{l}$ of the LMO slurry and annealing at $65^{\circ} \mathrm{C}$ until completely dry, resulting in LMO-GCD. Next, the LMO-GCDs were immersed in synthetic saliva and then first underwent a galvanostatic delithiation for different times followed by PXRD measurements on a powder diffractometer. Subsequently, the LMO-GCDs were re-immersed in synthetic saliva to perform the lithiation in an LSV experiments as described above. The galvanostatic treatment for the three samples was performed so that the first sample was stopped within the first plateau, the second sample after the first step within the second plateau and the third sample after the second step (Figure 4a, denoted as $A, B$ and $C$ ). From the PXRD analysis, three different structures can be distinguished, which are the structure of the initial $\mathrm{LiMn}_{2} \mathrm{O}_{4}$, of $\mathrm{Li}_{0.5} \mathrm{Mn}_{2} \mathrm{O}_{4}$ and of the fully delithiated $\lambda-\mathrm{Mn}_{2} \mathrm{O}_{4}$, as expected for the delithiation steps of $\mathrm{LiMn}_{2} \mathrm{O}_{4} \cdot{ }^{46}$ As shown in Figure SI.7, the PXRD patterns taken for the first, second and third sample (black, green and turquoise, respectively) imply that the initial $\mathrm{LiMn}_{2} \mathrm{O}_{4}$ structure type remains intact during the first plateau (with the composition $\mathrm{Li}_{x} \mathrm{Mn}_{2} \mathrm{O}_{4}$, with $0.5<\mathrm{x} \leq 1.0$ ) whilst the $\mathrm{Li}_{0.5} \mathrm{Mn}_{2} \mathrm{O}_{4}$ structure type is formed after the first step and remains intact during the second plateau (with the composition $\mathrm{Li}_{\mathrm{x}} \mathrm{Mn}_{2} \mathrm{O}_{4}$, with $0.0<\mathrm{x} \leq 0.5$ ). The $\lambda-\mathrm{Mn}_{2} \mathrm{O}_{4}$ is formed after the second step only when the structure contains no lithium. For the latter two, a small part of the sample remains in the initial $\mathrm{LiMn}_{2} \mathrm{O}_{4}$ structure type, possibly due to larger particles that are not completely delithiated. After the (re-)lithiation in the LSV experiment, for the first sample no structural differences can be observed, while the second sample is mainly transformed back to the initial $\mathrm{LiMn}_{2} \mathrm{O}_{4}$ structure type. For the 
sample that mainly consisted of the $\lambda-\mathrm{MnO}_{2}$, after the LSV measurement, a mixture of all three structure types (dominantly the $\mathrm{Li}_{0.5} \mathrm{Mn}_{2} \mathrm{O}_{4}$ structure type) was found. These results demonstrate how the delithiation/lithiation process becomes more irreversible with each structural transition passed in the delithiation process. This effect is already obvious in the LSV experiment after a delithiation for 20 min as seen in Figure 4b. While after the 20 min delithiation step only the first structural transition is approached, the LSV response already becomes broadened compared to all experiments with shorter delithiation steps. On the other hand, for delithiation times where the initial structure of $\operatorname{LiMn}_{2} \mathrm{O}_{4}$ remains intact (Figure $4 \mathrm{~b}, 20 \mathrm{~s}$ to $5 \mathrm{~min}$ ), the LSV signal is sharp and well defined with the peak current mainly varying with the delithiation time, meaning the amount of delithiated lithium. Therefore, the galvanostatic delithiation has to remain within the first plateau to avoid any structural changes.

In summary, the working mechanism of the electrode toward the detection of $\mathrm{Li}^{+}$is as follows. The $\mathrm{LiMn}_{2} \mathrm{O}_{4}$ was first oxidised under galvanostatic delithiation control leading to partial expulsion of $\mathrm{Li}^{+}$from $\mathrm{LiMn}_{2} \mathrm{O}_{4}$ (Eq.1):

$$
\mathrm{LiMn}_{2} \mathrm{O}_{4}-x e^{-} \rightleftharpoons \mathrm{Li}_{(1-x)} \mathrm{Mn}_{2} \mathrm{O}_{4}+x \mathrm{Li}^{+}
$$

Typically, the galvanostatic oxidation was stopped when a substantial amount of delithiated $\mathrm{Li}_{(1-x)} \mathrm{Mn}_{2} \mathrm{O}_{4}$ had formed ( $x=0.13$ ), taking care not to go beyond $x=0.5$ which would involve a phase transition. ${ }^{46}$ This requires driving the electrode for a period of 45 seconds at a current of $0.6 \mathrm{~mA}$ (current density of ca. $8.6 \mathrm{~mA} \mathrm{~cm} \mathrm{c}^{-2}$ ) and $10.0 \mu \mathrm{A}$ (current density of ca. $80.0 \mu \mathrm{A} \mathrm{cm} \mathrm{cm}^{-2}$ ) for a LMOmodified glassy carbon electrode (LMO-GCE) and a LMO-modified screen-printed electrode (LMOSPE), respectively. The electrode potential then typically reached a value of ca. $0.70 \mathrm{~V}$ vs SCE (for LMO$\mathrm{GCE}$ ) or ca. $0.52 \mathrm{~V}$ vs $\mathrm{Ag} / \mathrm{AgCl}$ (for LMO-SPE). Subsequently, the potential was swept from the end potential of the galvanostatic delithiation to $0.0 \mathrm{~V}$ vs SCE or $0.0 \mathrm{~V}$ vs $\mathrm{Ag} / \mathrm{AgCl}$. This led to the reinsertion of $\mathrm{Li}^{+}$in the reverse of reaction (Eq.1) as revealed by a cathodic peak in the linear sweep voltammogram. The peak current from the lithiation reflects both the amount of $\mathrm{Li}^{+}$that was expelled in the first step (galvanostatic delithiation) and that present in the solution phase before the analysis, which one aims to detect.

The sensitivity of the sensor was studied by employing the established sensing strategy as described above. The LMO-GCE was exposed in various concentrations of $\mathrm{Li}^{+}$-spiked synthetic saliva samples, ranging from $50.0 \mu \mathrm{M}$ to $5.0 \mathrm{mM}$ (Figure 5a). The measurable lower limit was determined by the absolute peak current value at the minimum peak position. As shown in Figure 5b, the absolute peak current value is increased with increasing $\mathrm{Li}^{+}$concentrations added into the synthetic saliva. A linear peak current behaviour was found at concentrations ranging from $50.0 \mu \mathrm{M}$ to $0.5 \mathrm{mM} \mathrm{Li}^{+}$with an $\mathrm{R}^{2}=0.9906$ (Figure 5b, inset). A measurable lower limit of $50.0 \mu \mathrm{M}$ was achieved, same value as found in aqueous solution (see Electrochemical Behaviour of LMO-GCE in Aqueous Solution). 

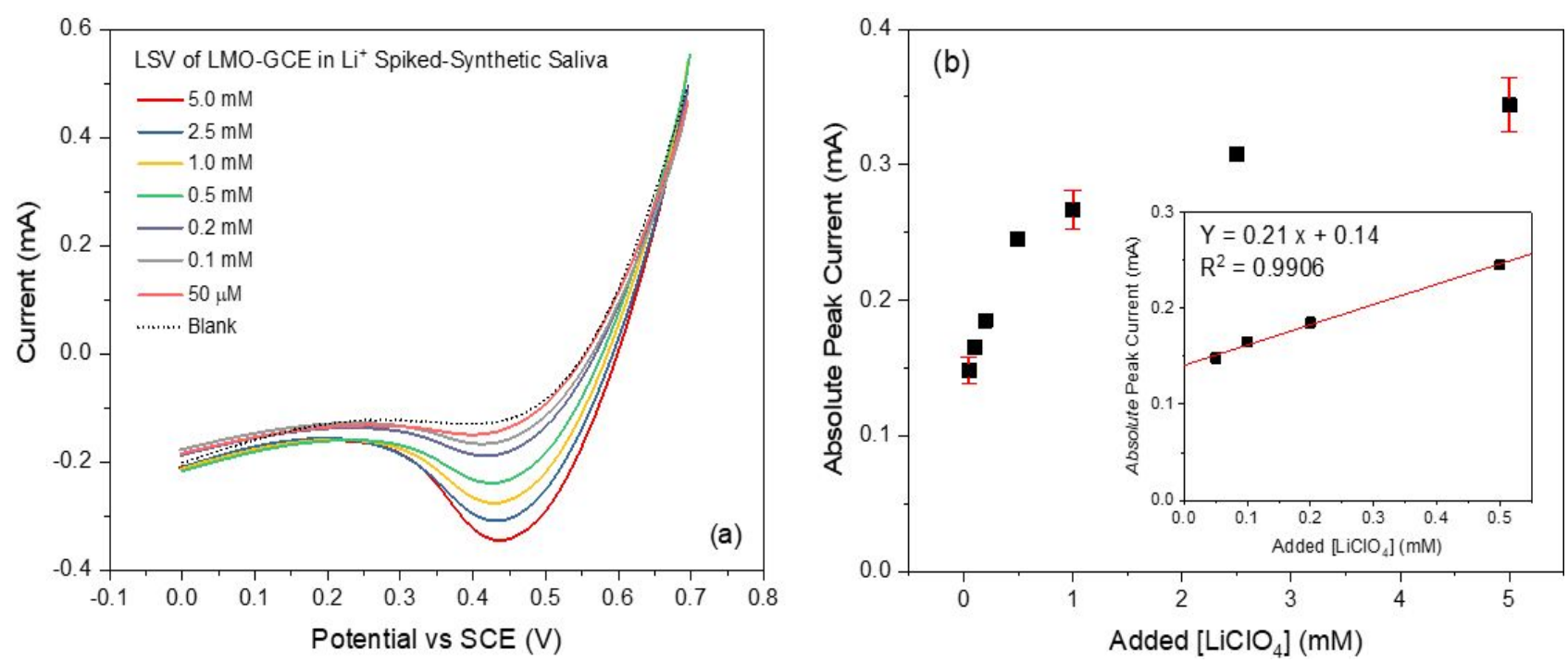

Figure 5. Measurable lower limit of the LMO-GCE in different concentrations of $\mathrm{Li}^{+}$-spiked synthetic saliva at a scan rate of $5.0 \mathrm{mV} \mathrm{s}^{-1}$. (a) LSVs of LMO-GCE, (b) A plot of the peak current values against various $\mathrm{Li}^{+}$-spiked synthetic saliva concentrations.

Having defined a measurable lower limit of $\mathrm{Li}^{+}$at the LMO-GCE in both aqueous solution and synthetic saliva, the following section will describe the applicability of the optimised system in authentic human saliva.

Detection of $\mathbf{L i}^{+}$in Authentic Human Saliva. Next the optimised methodology developed above was transferred to screen-printed electrodes and used to analyse lithium ions in authentic human saliva.

Initially, the LMO-SPE performance was characterised using CV in $1.0 \mathrm{M} \mathrm{LiCl}$, synthetic saliva or authentic human saliva. $50.0 \mu \mathrm{L}$ of the selected sample was deposited onto LMO-SPE surface, covering all three electrodes. A CV was recorded by sweeping the potential from $0.0 \mathrm{~V}$ to $1.2 \mathrm{~V}$ and back to $0.0 \mathrm{~V}$ vs $\mathrm{Ag} / \mathrm{AgCl}$ at a scan rate of $0.5 \mathrm{mV} \mathrm{s}^{-1}$. As shown in Figure 6 (red curve), two quasireversible anodic peaks are observed at a potential of ca. $0.74 \mathrm{~V}$ and ca. $0.88 \mathrm{~V}$ vs $\mathrm{Ag} / \mathrm{AgCl}$, which correspond to the two delithiation steps in $\mathrm{LiMn}_{2} \mathrm{O}_{4}$. On the backward scans, two cathodic peaks were also observed at a potential of ca. $-0.70 \mathrm{~V}$ and ca. $-0.82 \mathrm{~V}$ vs $\mathrm{Ag} / \mathrm{AgCl}$ that correspond to the reinsertion of the $\mathrm{Li}^{+}$(lithiation) into the spinel structure of LMO. This result suggests an excellent analytical performance of LMO-SPE than LMO-GCE (Figure 1) with two well-distinguished peaks observed clearly. In addition, exposing either synthetic saliva or authentic human saliva to the LMOSPE the anodic peaks (ca. $0.55 \mathrm{~V}$ and ca. $0.71 \mathrm{~V}$ vs $\mathrm{Ag} / \mathrm{AgCl}$ ) and cathodic peaks (ca. $-0.60 \mathrm{~V}$ and ca. $0.47 \mathrm{~V}$ vs $\mathrm{Ag} / \mathrm{AgCl}$ ) are again clearly observed (Figure 6, blue and black curves). Figure 6 shows that the SPE gives a clearer electrochemical response compared to the GCE (Figure SI.6a). 


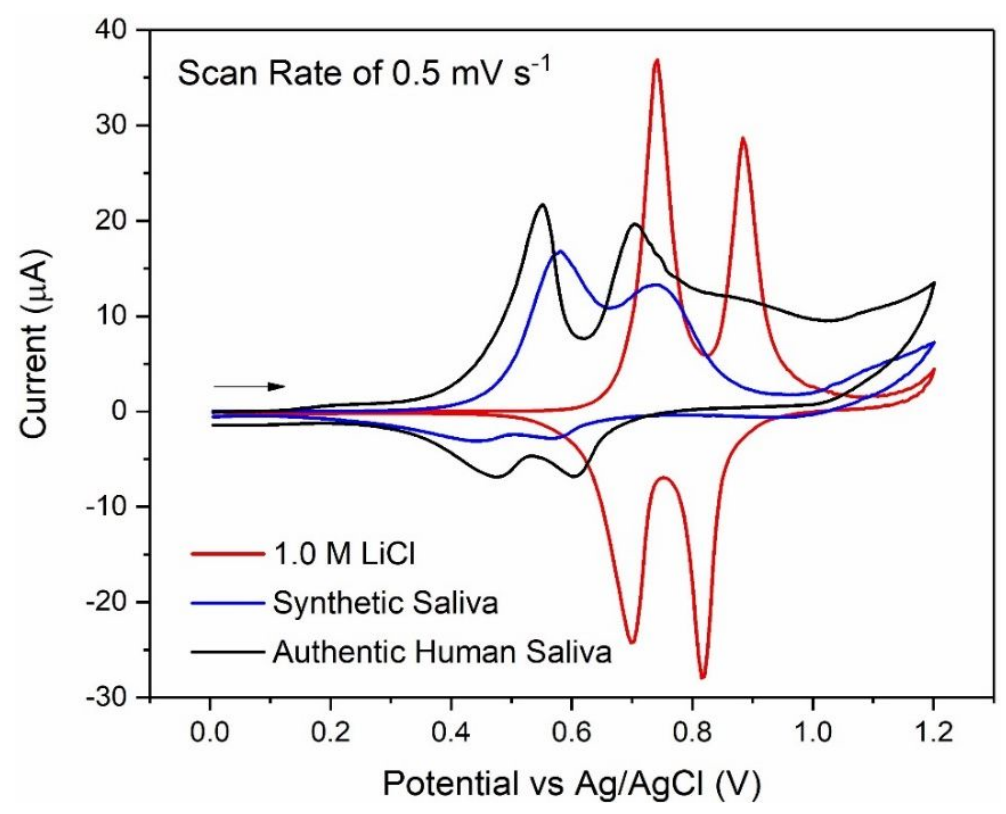

Figure 6. CV of LMO-SPE with different analytes at a scan rate of $0.5 \mathrm{mV} \mathrm{s}^{-1}$. Note that the potential of the SPE $\mathrm{Ag} / \mathrm{AgCl}$ reference electrode is poised by the chloride ion levels present explaining the shift in peak potentials between the analytes.

To conduct analysis of $\mathrm{Li}^{+}$in authentic human saliva, a ca. $50.0 \mu \mathrm{L}$ sample of pristine authentic human saliva was put onto the LMO-SPE surface. Subsequently, galvanostatic delithiation was performed with a current density of $80.0 \mu \mathrm{A} \mathrm{cm} \mathrm{cm}^{-2}$ for 45 seconds (see above). Next, an LSV measurement was undertaken immediately by sweeping the potential from the ending potential of the galvanostatic step (approximately $0.5 \mathrm{~V}$ vs $\mathrm{Ag} / \mathrm{AgCl}$ ) to $0.0 \mathrm{~V}$ vs $\mathrm{Ag} / \mathrm{AgCl}$ at a scan rate of $5.0 \mathrm{mV} \mathrm{s}^{-1}$ (Figure $7 \mathrm{a}$, solid red curve). To determine the $\mathrm{Li}^{+}$concentration in authentic human saliva, the standard addition procedure was conducted by adding $\mathrm{LiClO}_{4}$ standard solution with a known concentration of $100.0 \mathrm{mM}$ in subsequent steps to the sample (Figure 7a). Three different authentic human saliva samples were measured up to $1.0 \mathrm{mM} \mathrm{Li}^{+}$added, while for a fourth sample the added concentration range was extended up to $5.0 \mathrm{mM} \mathrm{Li}^{+}$to cover the therapeutic range $\left(1.5-2.5 \mathrm{mM} \mathrm{Li}^{+}\right)$. For each step the same galvanostatic delithiation and LSV measurements were performed. This procedure was repeated for three fractions from each of the four different authentic human saliva samples in order to ensure the reproducibility of the result and to determine the relative standard deviation (\% RSD). A plot of the absolute peak current values against the total concentration of $\mathrm{Li}^{+}$was then generated. In a control experiment (triplicate) synthetic saliva containing no $\mathrm{Li}^{+}$was used. As shown in Figure SI.9 and Figure 7b, the absolute peak current values increase linearly with increasing concentration of $\mathrm{Li}^{+}$-spiked authentic human saliva for the triplicate measurements of all four different samples in the respective concentration ranges. Additionally, the recovery of $\mathrm{Li}^{+}$was determined for the same authentic human saliva samples as before with an added $0.2 \mathrm{mM}$ concentration of $\mathrm{Li}^{+}$. The recovery was calculated from the differences between the $\mathrm{Li}^{+}$concentrations found from standard addition (before spiking) and the $\mathrm{Li}^{+}$concentrations found in the recovery test (after spiking) in relation to the spiked amount of $0.2 \mathrm{mM} \mathrm{Li}^{+}$. The summary of these results is reported in the Table 1 . 

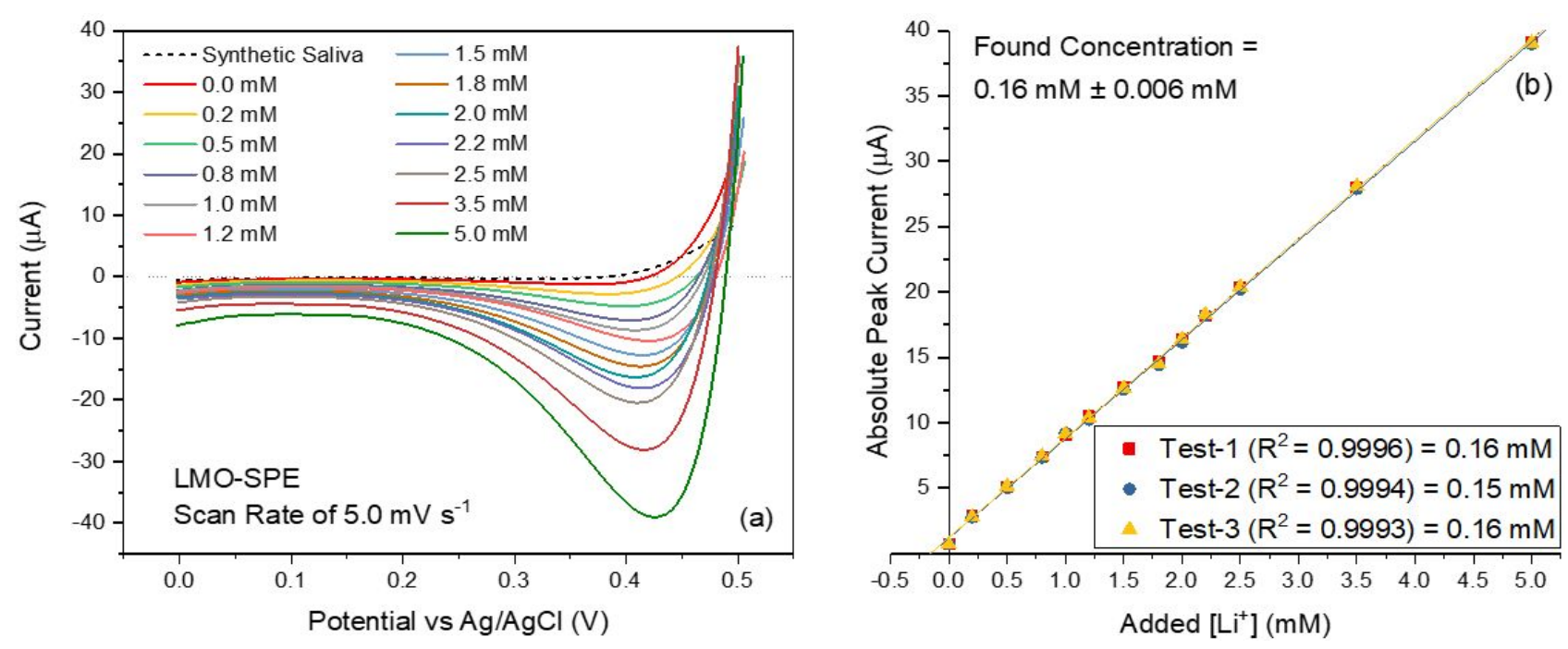

Figure 7. Linearity of the measurement. (a) Representative LSVs of LMO-SPE with different $\mathrm{Li}^{+}$-spiked authentic human saliva concentrations, at a scan rate of $5.0 \mathrm{mV} \mathrm{s}^{-1}$. (b) Linear peak current behaviour at various $\mathrm{Li}^{+}$-spiked authentic human saliva concentrations.

The first three samples analysed are similar (ranging from 0.13 to $0.16 \mathrm{mM}$ ) in around the value for a healthy person. Moreover, the relative standard deviation (\% RSD) from the random error was found to be $6.3 \%, 6.9 \%$ and $4.6 \%$ for sample- 1 , sample- 2 and sample-3, respectively. Together with the measurement of the zero $\mathrm{Li}^{+}$current, the systematical and random errors add up to $0.05,0.05$ and 0.04 , respectively. For the fourth sample, the standard addition method was extended towards the therapeutic range and beyond, demonstrating the linearity of the sensor response in the whole relevant range. As shown in Figure $7 \mathrm{~b}$, the found concentration in the fourth sample is $0.16 \pm 0.006$ $\mathrm{mM}$ (RSD 3.8\%) comparable to the values from the first three samples. This result shows a reproducible linear response of the sensor also in an extended range, including the therapeutically relevant concentrations as a linear response is seen up to $5.0 \mathrm{mM} \mathrm{Li}^{+}$. This is also in agreement with the experiments shown previously (see Electrochemical Behaviour of LMO-GCE in Aqueous Solution) using the LMO-SPE with potentiostatic delithiation (holding the potential of $1.0 \mathrm{~V}$ vs SCE for $10 \mathrm{~min}$ prior to the LSV) for detection of $\mathrm{Li}^{+}$in aqueous solution. The result demonstrates the practicality of the sensor for routine monitoring of $\mathrm{Li}^{+}$in saliva for patient with bipolar disease.

Table $1 . \mathrm{Li}^{+}$quantification in authentic human saliva samples and recovery results

\begin{tabular}{|c|c|c|c|}
\hline Sample & Concentration (before spiking) & RSD & $\begin{array}{c}\text { Recovery (after spiking } \\
\text { with } 0.2 \mathrm{mM} \mathrm{Li}^{+} \text {) }\end{array}$ \\
\hline 1 & $0.16 \pm 0.0100 \mathrm{mM}$ & $6.3 \%$ & $99.2 \%$ \\
\hline 2 & $0.14 \pm 0.0096 \mathrm{mM}$ & $6.9 \%$ & $99.0 \%$ \\
\hline 3 & $0.13 \pm 0.0060 \mathrm{mM}$ & $4.6 \%$ & $98.6 \%$ \\
\hline 4 & $0.16 \pm 0.0060 \mathrm{mM}$ & $3.8 \%$ & $99.4 \%$ \\
\hline
\end{tabular}




\section{CONCLUSIONS}

The electrochemical sensor based on a lithium manganese oxide $\left(\mathrm{LiMn}_{2} \mathrm{O}_{4}\right)$-modified screenprinted electrode (LMO-SPE) exhibits a good selectivity towards possible interfering cations, a sensitivity of $50.0 \mu \mathrm{M}$ (in both aqueous solution and synthetic saliva) and an excellent sensing performance in authentic human saliva. The linear response range of the sensor spans the therapeutically relevant $\mathrm{Li}^{+}$concentrations in human saliva and allows analysis in reasonable times of less than three minutes.

The sensor offers a low cost and easy to utilise alternative that is applicable for routine monitoring of $\mathrm{Li}^{+}$levels. With the non-invasive sampling approach the sensor can be used directly by either patients or clinicians. For instance, patients with bipolar disease can benefit from the point-ofcare diagnosis with this sensor, as during dose adjustment or change in the medication schedule, immediate feedback is possible. This ensures that the $\mathrm{Li}^{+}$levels remain within the therapeutic range, so patients are treated appropriately and safely.

\section{ASSOCIATED CONTENT}

Supporting Information Available: The following files are available free of charge.

Additional figures (Figures SI.1 to SI.9) for (a) electrochemical behaviour of LMO-GCE in aqueous solution, (b) detection of $\mathrm{Li}^{+}$in synthetic saliva and (c) detection of $\mathrm{Li}^{+}$in authentic human saliva; Table SI.1 compositions of different synthetic saliva recipes; and SI. Calculations for current density of the LMO-GCE and LMO-SPE.

\section{AUTHOR INFORMATION}

\section{Corresponding Author}

*E-mail: richard.compton@chem.ox.ac.uk

\section{ORCID}

Richard G. Compton: 0000-0001-9841-5041

\section{Notes}

The authors declare no competing financial interest.

\section{ACKNOWLEDGEMENTS}

The authors thank Professor Simon J. Clarke (Department of Chemistry, Oxford University) for the provision of the X-ray diffraction facilities. A.L.S. thanks the Indonesian government through the Indonesia Endowment Fund Scholarships (S-3453/LPDP.3/2016) for funding. B.R. acknowledges the financial support from the German Research Foundation (DFG) through the Research Fellowship RA 3120/1-1. 


\section{REFERENCES}

(1) Merikangas, K. R.; Jin, R.; He, J. P.; Kessler, R. C.; Lee, S.; Sampson, N. A.; Viana, M. C.; Andrade, L. H.; Hu, C.; Karam, E. G.; et al. Prevalence and Correlates of Bipolar Spectrum Disorder in the World Mental Health Survey Initiative. Arch. Gen. Psychiatry 2011, 68(3), 241-251.

(2) Rybakowski, J. K. Recent Advances in the Understanding and Management of Bipolar Disorder in Adults [Version 1; Peer Review: 2 Approved]. F1000Research 2017, 6 (2033), 1-7.

(3) NHS. https://www.nhs.uk/conditions/bipolar-disorder/treatment/. Accessed on 5 April 2019.

(4) WHO. 20 $0^{\text {th }}$ World Health Organization (WHO) Essential Medicines List https://www.who.int/medicines/publications/essentialmedicines/en/. Accessed on 9 April 2019.

(5) Murru, A.; Torra, M.; Callari, A.; Pacchiarotti, I.; Romero, S.; de la Presa, B. G.; Varo, C.; Goikolea, J. M.; Pérez-Sola, V.; Vieta, E.; et al. A Study on the Bioequivalence of Lithium and Valproate Salivary and Blood Levels in the Treatment of Bipolar Disorder. Eur. Neuropsychopharmacol. 2017, 27 (8), 744-750.

(6) Thase, M. E.; Sachs, G. S. Bipolar Depression: Pharmacotherapy and Related Therapeutic Strategies. Biol. Psychiatry 2000, 48 (6), 558-572.

(7) Albero, M. I.; Ortuño, J. A.; García, M. S.; Cuartero, M.; Alcaraz, M. C. Novel Flow-through Bulk Optode for Spectrophotometric Determination of Lithium in Pharmaceuticals and Saliva. Sensors Actuators B Chem. 2010, 145 (1), 133-138.

(8) Ben-Aryeh, H.; Naon, H.; Szargel, R.; Gutman, D.; Hefetz, A. Salivary Lithium Concentration-A Tool for Monitoring Psychiatric Patients. Oral Surgery, Oral Med. Oral Pathol. 1980, 50 (2), 127129.

(9) Lima, D. P.; Diniz, D. G.; Moimaz, S. A. S.; Sumida, D. H.; Okamoto, A. C. Saliva: Reflection of the Body. Int. J. Infect. Dis. 2010, 14 (3), e184-e188.

(10) Kim, J.; Valdés-Ramírez, G.; Bandodkar, A. J.; Jia, W.; Martinez, A. G.; Ramírez, J.; Mercier, P.; Wang, J. Non-Invasive Mouthguard Biosensor for Continuous Salivary Monitoring of Metabolites. Analyst 2014, 139 (7), 1632-1636.

(11) Ngamchuea, K.; Chaisiwamongkhol, K.; Batchelor-McAuley, C.; Compton, R. G. Chemical Analysis in Saliva and the Search for Salivary Biomarkers - a Tutorial Review. Analyst 2018, 143 (1), 8199.

(12) Hirayama, E.; Sugiyama, T.; Hisamoto, H.; Suzuki, K. Visual and Colorimetric Lithium Ion Sensing Based on Digital Color Analysis. Anal. Chem. 2000, 72 (3), 465-474.

(13) Dai, L.; Wigman, L.; Zhang, K. Sensitive and Direct Determination of Lithium by Mixed-Mode Chromatography and Charged Aerosol Detection. J. Chromatogr. A 2015, 1408, 87-92.

(14) Vrouwe, E. X.; Luttge, R.; van den Berg, A. Direct Measurement of Lithium in Whole Blood Using Microchip Capillary Electrophoresis with Integrated Conductivity Detection. Electrophoresis 2004, 25 (10-11), 1660-1667.

(15) Lewen, N.; Nugent, D. The Use of Inductively Coupled Plasma-Atomic Emission Spectroscopy 
(ICP-AES) in the Determination of Lithium in Cleaning Validation Swabs. J. Pharm. Biomed. Anal. 2010, 52 (5), 652-655.

(16) Stubing, D. B.; Heng, S.; Abell, A. D. Crowned Spiropyran Fluoroionophores with a Carboxyl Moiety for the Selective Detection of Lithium Ions. Org. Biomol. Chem. 2016, 14 (15), 37523757.

(17) Cloete, K. J.; Jenčič, B.; Šmit, Ž.; Kelemen, M.; Mkentane, K.; Pelicon, P. Detection of Lithium in Scalp Hair by Time-of-Flight Secondary Ion Mass Spectrometry with High Energy (MeV) Primary Ions. Anal. Methods 2017, 9, 5249-5253.

(18) Sweilam, M. N.; Varcoe, J. R.; Crean, C. Fabrication and Optimization of Fiber-Based Lithium Sensor: A Step toward Wearable Sensors for Lithium Drug Monitoring in Interstitial Fluid. ACS Sensors 2018, 3 (9), 1802-1810.

(19) Novell, M.; Guinovart, T.; Blondeau, P.; Rius, F. X.; Andrade, F. J. A Paper-Based Potentiometric Cell for Decentralized Monitoring of Li Levels in Whole Blood. Lab Chip 2014, 14 (7), 13081314.

(20) Kadian, S.; Arya, B. D.; Kumar, S.; Sharma, S. N.; Chauhan, R. P.; Srivastava, A.; Chandra, P.; Singh, S. P. Synthesis and Application of $\mathrm{PHT}_{-} \mathrm{TiO}_{2}$ Nanohybrid for Amperometric Glucose Detection in Human Saliva Sample. Electroanalysis 2018, 30 (11), 2793-2802.

(21) Gugoasa, L. A.; Stefan-van Staden, R.-I.; van Staden, J. F.; Coroș, M.; Pruneanu, S. Electrochemical Determination of Bisphenol A in Saliva by a Novel Three-Dimensional (3D) Printed GoldReduced Graphene Oxide (RGO) Composite Paste Electrode. Anal. Lett. 2019, 1-24.

(22) Ngamchuea, K.; Batchelor-McAuley, C.; Compton, R. G. The Fate of Silver Nanoparticles in Authentic Human Saliva. Nanotoxicology 2018, 12 (4), 305-311.

(23) Hardcastle, J. L.; West, C. E.; Compton, R. G. The Membrane Free Sonoelectroanalytical Determination of Trace Levels of Lead and Cadmium in Human Saliva. Analyst 2002, 127, 14951501.

(24) Sanna, G.; Pilo, M. I.; Piu, P. C.; Spano, N.; Tapparo, A.; Seeber, R. Microelectrodes for the Determination of Heavy Metal Traces in Physiological Conditions. $\mathrm{Hg}$, $\mathrm{Cu}$ and $\mathrm{Zn}$ Ions in Synthetic Saliva. Electroanalysis 2002, 14 (21), 1512-1520.

(25) Khairy, M.; Kadara, R. O.; Kampouris, D. K.; Banks, C. E. In Situ Bismuth Film Modified Screen Printed Electrodes for the Bio-Monitoring of Cadmium in Oral (Saliva) Fluid. Anal. Methods 2010, 2 (6), 645-649.

(26) Kämäräinen, S.; Mäki, M.; Tolonen, T.; Palleschi, G.; Virtanen, V.; Micheli, L.; Sesay, A. M. Disposable Electrochemical Immunosensor for Cortisol Determination in Human Saliva. Talanta 2018, 188, 50-57.

(27) Pasha, S. K.; Kaushik, A.; Vasudev, A.; Snipes, S. A.; Bhansali, S. Electrochemical Immunosensing of Saliva Cortisol. J. Electrochem. Soc. 2014, 161 (2), B3077-B3082.

(28) Goodwin, A.; Banks, C. E.; Compton, R. G. Tagging of Model Amphetamines with Sodium 1,2- 
Naphthoquinone-4-Sulfonate: Application to the Indirect Electrochemical Detection of Amphetamines in Oral (Saliva) Fluid. Electroanalysis 2006, 18 (18), 1833-1837.

(29) Ponnaiah, S. K.; Prakash, P.; Vellaichamy, B.; Paulmony, T.; Selvanathan, R. Picomolar-Level Electrochemical Detection of Thiocyanate in the Saliva Samples of Smokers and Non-Smokers of Tobacco Using Carbon Dots Doped $\mathrm{Fe}_{3} \mathrm{O}_{4}$ Nanocomposite Embedded on g- $\mathrm{C}_{3} \mathrm{~N}_{4}$ Nanosheets. Electrochim. Acta 2018, 283, 914-921.

(30) Goodwin, A.; Banks, C. E.; Compton, R. G. Graphite Micropowder Modified with 4-Amino-2,6Diphenylphenol Supported on Basal Plane Pyrolytic Graphite Electrodes: Micro Sensing Platforms for the Indirect Electrochemical Detection of $\Delta 9$-Tetrahydrocannabinol in Saliva. Electroanalysis 2006, 18 (11), 1063-1067.

(31) Lee, P. T.; Goncalves, L. M.; Compton, R. G. Electrochemical Determination of Free and Total Glutathione in Human Saliva Samples. Sensors Actuators, B Chem. 2015, 221, 962-968.

(32) Ngamchuea, K.; Batchelor-Mcauley, C.; Cowen, P. J.; Williams, C.; Gonçalves, L. M.; Compton, R. G. Can Saliva Testing Replace Blood Measurements for Health Monitoring? Insights from a Correlation Study of Salivary and Whole Blood Glutathione in Humans. Analyst 2016, 141 (15), 4707-4712.

(33) Ngamchuea, K.; Batchelor-McAuley, C.; Compton, R. G. Understanding Electroanalytical Measurements in Authentic Human Saliva Leading to the Detection of Salivary Uric Acid. Sensors Actuators, B Chem. 2018, 262, 404-410.

(34) dos Santos, W. T. P.; Amin, H. M. A.; Compton, R. G. A Nano-Carbon Electrode Optimized for Adsorptive Stripping Voltammetry: Application to Detection of the Stimulant Selegiline in Authentic Saliva. Sensors Actuators, B Chem. 2019, 279, 433-439.

(35) dos Santos, W. T. P.; Compton, R. G. A Simple Method to Detect the Stimulant Modafinil in Authentic Saliva Using a Carbon-Nanotube Screen-Printed Electrode with Adsorptive Stripping Voltammetry. Sensors Actuators B Chem. 2019, 285, 137-144.

(36) Zhu, Q.; Zheng, S.; Lu, X.; Wan, Y.; Chen, Q.; Yang, J.; Zhang, L.; Lu, Z. Improved Cycle Performance of $\mathrm{LiMn}_{2} \mathrm{O}_{4}$ Cathode Material for Aqueous Rechargeable Lithium Battery by LaF ${ }_{3}$ Coating. J. Alloys Compd. 2016, 654, 384-391.

(37) Özgür, C. Preparation and Characterization of $\mathrm{LiMn}_{2} \mathrm{O}_{4}$ Ion-Sieve with High $\mathrm{Li}^{+}$Adsorption Rate by Ultrasonic Spray Pyrolysis. Solid State Ionics 2010, 181 (31), 1425-1428.

(38) Ryu, T.; Shin, J.; Ghoreishian, S. M.; Chung, K.-S.; Huh, Y. S. Recovery of Lithium in Seawater Using a Titanium Intercalated Lithium Manganese Oxide Composite. Hydrometallurgy 2019, 184, $22-$ 28.

(39) Zampardi, G.; Batchelor-McAuley, C.; Kätelhön, E.; Compton, R. G. Lithium-Ion-Transfer Kinetics of Single $\mathrm{LiMn}_{2} \mathrm{O}_{4}$ Particles. Angew. Chemie 2017, 129 (2), 656-659.

(40) Zdrachek, E.; Bakker, E. Potentiometric Sensing. Anal. Chem. 2019, 91 (1), 2-26.

(41) Synthetic Urine e.K. https://www.synthetic-urine.de/en/produkt/synthetic-saliva-din-53160- 
1-din-en-6462006-07/. Accessed on 14 August 2019.

(42) WinXPow. Program for the Collection and the Evaluation of X-Ray Powder Data. STOE \& Cie GmbH, Darmstadt, Germany (1999).

(43) Origin2017. OriginLab, Northhampton, Massachuetts, USA (2017).

(44) CUREC (Approved Procedure 24: IDREC 24 Version 3.0, Research Support, University of Oxford). https://researchsupport.admin.ox.ac.uk/governance/ethics/resources/ap. Accessed on 14 August 2019.

(45) Salivette ${ }^{\circledR}$ Saliva Examination, Sarstedt AG \& Co. KG (Instructions for use Salivetts ${ }^{\circledR}$ Cortisol). https://www.sarstedt.com/en/products/diagnostic/salivasputum/product/51.1534/. Accessed on 14 August 2019.

(46) Bianchini, M.; Fauth, F.; Suard, E.; Leriche, J.-B.; Masquelier, C.; Croguennec, L. Spinel Materials for Li-Ion Batteries: New Insights Obtained by Operando Neutron and Synchrotron X-Ray Diffraction. Acta Crystallogr. Sect. B 2015, 71 (6), 688-701.

\section{Graphical Abstract}

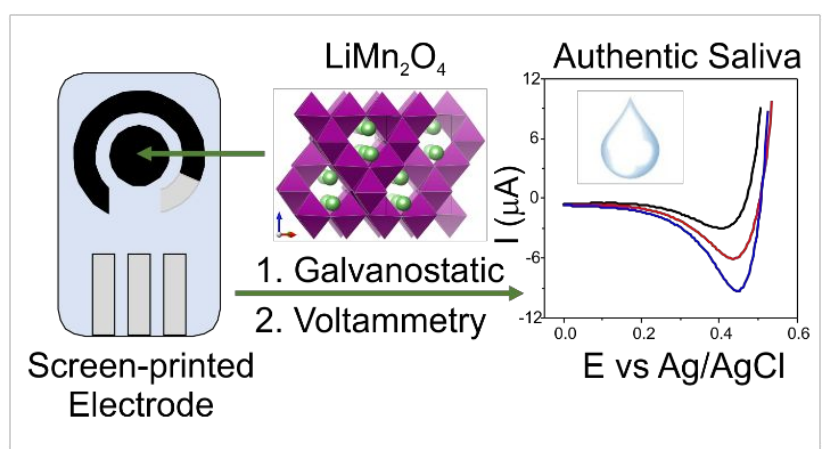

